\title{
Tai Chi-based exercise program provided via telerehabilitation compared to home visits in a post-stroke population who have returned home without intensive rehabilitation: study protocol for a randomized, non-inferiority clinical trial
}

Michel Tousignant ${ }^{1,2^{*}}$, Hélène Corriveau ${ }^{1,2}$, Dahlia Kairy ${ }^{3}$, Katherine Berg ${ }^{4}$, Marie-France Dubois ${ }^{1,2}$, Sylvie Gosselin ${ }^{1}$, Richard H Swartz ${ }^{4}$, Jean-Martin Boulanger ${ }^{1}$ and Cynthia Danells ${ }^{5}$

\begin{abstract}
Background: The incidence of strokes in industrialized nations is on the rise, particularly in the older population. In Canada, a minority of individuals who have had a stroke actually receive intensive rehabilitation because most stroke patients do not have access to services or because their motor recovery was judged adequate to return home. Thus, there is a considerable need to organize home-based rehabilitation services for everyone who has had a stroke. To meet this demand, telerehabilitation, particularly from a service center to the patient's home, is a promising alternative approach that can help improve access to rehabilitation services once patients are discharged home.

Methods/Design: This non-inferiority study will include patients who have returned home post-stroke without requiring intensive rehabilitation. To be included in the study, participants will: 1) not be referred to an Intensive Functional Rehabilitation Unit, 2) have a Rankin score of 2 or 3, and 3) have a balance problem (Berg Balance Scale score between 46 and 54). Participants will be randomly assigned to either the teletreatment group or the home visits group. Except for the delivery mode, the intervention will be the same for both groups, that is, a personalized Tai Chi-based exercise program conducted by a trained physiotherapist (45-minute session twice a week for eight consecutive weeks). The main objective of this research is to test the non-inferiority of a Tai Chi-based exercise program provided via telerehabilitation compared to the same program provided in person at home in terms of effectiveness for retraining balance in individuals who have had a stroke but do not require intensive functional rehabilitation. The main outcome of this study is balance and mobility measured with the Community Balance and Mobility Scale. Secondary outcomes include physical and psychological capacities related to balance and mobility, participants' quality of life, satisfaction with services received, and cost-effectiveness associated with the provision of both types of services.
\end{abstract}

Study/trial registration: ClinicalTrials.gov: NCT01848080

Keywords: Balance, Stroke, Telerehabilitation, Tai Chi exercise program, Randomized controlled trial

\footnotetext{
* Correspondence: michel.tousignant@usherbrooke.ca

'Université de Sherbrooke, Sherbrooke, QC, Canada

${ }^{2}$ Research Center on Aging, University Institute of Geriatrics of Sherbrooke,

Sherbrooke, QC, Canada

Full list of author information is available at the end of the article
}

() Biomed Central

(c) 2014 Tousignant et al.; licensee BioMed Central Ltd. This is an Open Access article distributed under the terms of the Creative Commons Attribution License (http://creativecommons.org/licenses/by/2.0), which permits unrestricted use, distribution, and reproduction in any medium, provided the original work is properly cited. The Creative Commons Public Domain Dedication waiver (http://creativecommons.org/publicdomain/zero/1.0/) applies to the data made available in this article, unless otherwise stated. 


\section{Background}

The incidence of strokes in industrialized nations is on the rise, particularly in the older population. The risk of stroke doubles every ten years after age 55 [1]. The prognosis of functional recovery following a stroke depends on several factors, including initial severity of the injury, spontaneous recovery capacities and the impact of rehabilitation [2]. In older individuals, stroke sequelae can include sensorimotor, cognitive and perceptual impairments, which directly affect mobility and balance and thus drastically increase the risk of falls $[3,4]$. In fact, balance and ambulation problems are the most important fall risk factors following a stroke [5-7]. It has been shown that $75 \%$ of individuals who have had a stroke fall within the first six months following their discharge from hospital [3]. Consequently, balance is considered to be one of the most promising reversible risk factors to reduce falls $[8,9]$.

In Canada, only 10 to $15 \%$ of people who have had a stroke actually receive rehabilitation services [10]. Typically, rehabilitation is based on a multidisciplinary approach that begins during acute care and continues in an intensive functional rehabilitation unit (IFRU) and after discharge. However, 37\% of moderate-to-severe cases are transferred to a rehabilitation unit post-stroke [11]; the others return home with or without rehabilitation services [12,13], either because they live too far from a rehabilitation center or because their motor recovery was judged adequate for a safe return home $[14,15]$. Thus, there is a large number of individuals at home who need rehabilitation following their stroke but who do not have access to services [16]. Consequently, their mobility and balance decline, creating a significant risk for falls in this population.

The literature supports the need for outpatient rehabilitation services, at home or elsewhere for those who return home, regardless of the severity of their sequelae [17]. Unfortunately, the precarious nature of services has been well-documented in the Canadian Best Practice Recommendations for Stroke Care (updated 2013); it appears that the primary obstacle hindering best practice application in stroke care is the lack of human resources. With this in mind, the Best Practices Expert Consensus Panel prioritized certain recommendations, including facilitating outpatient and home-based rehabilitation services because of the inability of the healthcare system to meet current demands [18]. Therefore, it is essential to improve accessibility to rehabilitation services, as clearly indicated in the Quebec Homecare Support Policy $[18,19]$.

In this context, new alternative approaches need to be considered to deliver services at home. Telerehabilitation, defined as a telehealth application that uses telecommunication technologies to provide rehabilitation services, is a new approach in the rehabilitation field. It has been identified as a very promising alternative tool that could help improve access to healthcare services in general [20-25]. Furthermore, telerehabilitation has been identified as one of the three telehealth application areas prioritized by the Quebec Ministry of Health and Social Services [11]. A main advantage of this intervention method is that it allows patients to receive rehabilitation in their homes without having to travel to get healthcare services. This way of delivering services also addresses the shortage of professionals; with less time spent traveling, professionals can spend more time treating, which in turn improves access to services. It is therefore crucial to provide decisionmakers with evidence concerning the effectiveness of telerehabilitation applications.

Regardless of the rehabilitation delivery mode, the choice and type of exercise program varies from one study to the next. Recent studies have shown that a balance retraining program based on Tai Chi movements improved balance in individuals at risk of falls [26,27]. A Tai Chi-based exercise program, supervised by a physiotherapist, which uses movement repetition favoring directional adjustments in space has been shown to be effective in improving balance in individuals with physical impairments, including those presenting sequelae following a stroke. Two studies conducted by our research group demonstrated similar results in frail, older individuals [28,29]. A study conducted with older individuals with diabetes found that a simple sequence of Tai Chi movements improved their balance and attention capacity [29]. Another study conducted with frail, older individuals with balance problems showed that a Tai Chi intervention had a protective effect on the incidence of falls: for every person who had falls in the Tai Chi group, the conventional physiotherapy group had 1.3 people who had falls [29]. Furthermore, the Tai Chi intervention appeared to delay the onset of the first fall in older individuals, with $50 \%$ of participants in the physiotherapy group falling once after five months of follow-up, compared to after ten months of follow-up for $50 \%$ of participants in the Tai Chi group [30]. Even more interesting is the fact that these balance retraining programs based on Tai Chi movements are equally effective in older individuals following a stroke [31,32]. In fact, the first large-scale study [31] (Tai Chi group: $\mathrm{n}=74$; comparison group: $\mathrm{n}=62$ ) demonstrated the effectiveness of Tai Chi in improving balance compared to a conventional exercise program in individuals with chronic stroke. A second study [32] achieved the same results with 18 patients. Moreover, in a pre-/postintervention study with no control group, 17 balance impaired elders have undergone a structured, interactive, and supervised Tai Chi class from their own homes through a videoconferencing system to improve balance and reduce fear of falling. The results demonstrated the 
intervention was effective for improving balance and reducing fear of falling [33]. Finally, our pilot study demonstrated that Tai Chi practiced via supervised telerehabilitation was effective in improving balance and motor skills in six patients post-stroke.

The principal aim of this clinical trial is to test the noninferiority of a Tai Chi-based exercise program, provided via telerehabilitation compared to the same program provided in person at home, in terms of effectiveness for retraining balance in individuals who have had a stroke but do not require intensive functional rehabilitation. More specifically, the objectives are to:

1) Verify whether the gains in both physical and psychological capacities related to balance and mobility of patients treated by Tai Chi via telerehabilitation are not inferior to those receiving the same treatment in person at home;

2) Verify if the gain in quality of life of patients treated by Tai Chi via telerehabilitation is not inferior to the gain of those receiving the same treatment in person at home;

3) Verify if satisfaction with services received by patients treated by Tai Chi via telerehabilitation group is not inferior to satisfaction of those receiving the same treatment in person at home;

4) Compare the costs associated with the provision of the two types of services delivery, that is, via telerehabilitation and in person at home.

\section{Methods/Design}

\section{Study design}

The design of choice to determine the effectiveness of an experimental intervention compared to a standard intervention is the randomized controlled trial (RCT). Two groups will be formed: 1) telerehabilitation group, and 2) home visits group. We will use this design while considering that the prerequisites for undertaking a noninferiority RCT are met:

1) The plausibility that a balance retraining program based on Tai Chi movements has been shown to improve balance [34], and specifically in clients with stroke $[32,35]$.

2) The research procedures in telerehabilitation are well established in real-life situations, from both clinical and technological perspectives. Our team is at the forefront of conducting studies in home-based teletreatment following knee arthroplasty [30,36], in speech therapy [37], and in individuals with chronic obstructive pulmonary disease [38].

3) We conducted a pilot study in six patients post-stroke.

Figure 1 illustrates the research design and timeline.

\section{Participants}

The study population of interest will be individuals who have had a stroke and stayed in a hospital linked to one of the following sites: 1) Sherbrooke site (Centre Hospitalier Universitaire de Sherbrooke), 2) Montreal sites (Jewish Rehabilitation Hospital, Institut de Réadaptation GingrasLindsay-de-Montreal and Centre de Santé et de Services Sociaux Champlain-Charles-Le Moyne), and 3) Toronto site (Sunnybrook Health Sciences Center). Special care will be taken to ensure that participant eligibility will target individuals who have had a stroke and returned home without requiring intensive rehabilitation. We will base our selection on the Rankin classification [39] established by the treating neurologist or trained therapist during the hospitalization period. This classification system allows us to assign individuals who have had a stroke to one of four groups according to their level of functional impairment. Patients with a Rankin score of 2 generally present with mild impairments, maintain their autonomy and can perform all previous activities. Patients with a Rankin score of 3 present with moderate impairments and generally require moderate assistance with their activities of daily living. These patients are usually sent home with or without referral for physiotherapy services at home.

Therefore, a sample of participants aged 45 years and older will be recruited based on the following inclusion criteria: 1) have had a stroke with a Rankin score of 2 or 3; 2) not be referred to an IFRU and return home following discharge from hospital; 3) understand instructions to allow participation in evaluations and interventions; 4) have a balance problem as evidenced by a score between 46 and 54 on the Berg Balance Scale [40]; 5) have a caregiver who would be available during the telerehabilitation sessions to ensure safety during exercises; and 6) live in an area served by high speed Internet. Excluded will be individuals who present with: 1) a previous stroke episode in the last 12 months (other than the present one); 2) severe body hemineglect; 3 ) significant hemianopsia visual problems accompanied by hemineglect; 4) uncontrolled medical problems; and 5) moderate to severe aphasia.

Participants will be recruited during the hospitalization period by the team of treating nurses, physiotherapists and neurologists at each of the three sites (Sherbrooke, Montreal and Toronto). When the team decides that a patient will not require a referral to an IFRU and will return home (inclusion criteria 1 and 2), they will verify inclusion criteria 3 and 4 and exclusion criteria 1 to 5 from the medical chart. If patients are eligible based on these criteria, the hospital team will ask if they agree to be contacted by a research associate. If they agree, a research associate will visit them in hospital to inform them of the project and ask them to participate. The research associate will verify inclusion criteria 5 and 6 . If a patient meets all the criteria and is interested in participating in the study, 


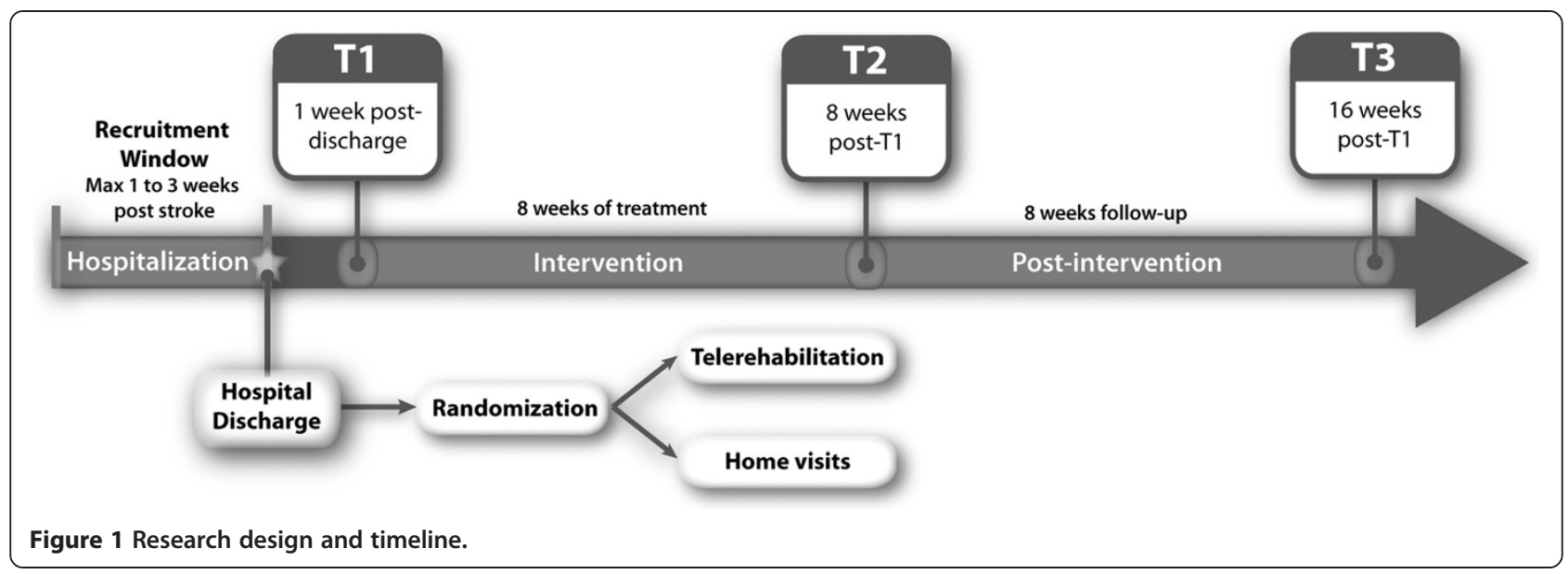

they will be asked to sign the consent form previously approved by the ethics committee at each recruitment site.

Once included, participants will be randomly assigned to either the telerehabilitation group or the home visits group by the coordinator of each recruitment site. This randomization will be performed using block randomization of sizes 2 and 4 done by a computer. Block size will not be known by the evaluators. This randomization will be performed following stratification based on the Rankin score (2 or 3), a variable that is likely to influence recovery prognosis. A system of numbered, sealed envelopes will be put in place.

\section{Ethics}

The study is being conducted in accordance with the Helsinki Declaration. It was approved by the Ethics Committee of each recruitment sites: 1) Sherbrooke - Centre Hospitalier Universitaire de Sherbrooke and Centre de Santé et de Services Sociaux de l'Institut Universitaire de Gériatrie de Sherbrooke; 2) Montréal - Centre de Recherche Interdisciplinaire en Réadaptation de Montréal Métropolitain; 3) Longueuil - Centre de Santé et de Services Sociaux Champlain-Charles-Le Moyne; 4) Toronto Sunnybrook Hospital. It has also been registered under www.clinicaltrials.gov (NCT01848080).

\section{Interventions}

A personalized exercise program based on Tai Chi was developed by our team for previous studies aiming to improve balance in older individuals with diabetes [28] and in frail, older individuals with balance problems [29]. This program was also used during the pilot study. The exercise program consists of movements based on a combination of alignments and body-specific orientations, weight transfers and changes in direction inspired by Tai Chi [41]. The exercises do not require any physical interaction between the Tai Chi instructor and participants. Optimal treatment frequency for patients in the subacute and chronic phases following a stroke is twice a week, as suggested by a systematic review [42].

For both groups, the interventions will start immediately after discharge from hospital. The rehabilitation exercise sessions will be conducted by a physiotherapist trained in the practice of Tai Chi. The sessions will last 45 minutes and take place twice a week for eight weeks. The only difference between the groups will be the delivery mode of the intervention, that is telerehabilitation or home visits.

\section{Outcomes}

All evaluations will be completed in the research centers/ hospitals of the three sites and will last approximately three hours. The first evaluation will be conducted at baseline, prior to starting intervention $\left(\mathrm{T}_{1}\right)$ to collect base measures on the participants' condition. A second evaluation will be conducted just after the two-month intervention $\left(\mathrm{T}_{2}\right)$ and the third evaluation will be four months $\left(\mathrm{T}_{3}\right)$ following discharge from the hospital. All evaluations will be carried out by evaluators trained in the standard procedures for all measures, who are independent and blinded to the intervention. Specific directions will be provided to the evaluators and the participants to ensure that intervention allocation remains anonymous.

To measure balance and functional mobility, the Community Balance and Mobility Scale (CB\&M) [43-45] will be used. This tool was developed for ambulatory individuals following a traumatic brain injury [43]. It has been validated in individuals following a stroke $[44,46]$. It assesses 19 tasks. The items are rated on a six-point scale (from $0=$ unable to perform, to $5=$ able to perform independently), for a maximum total score of 95 points. The CB\&M has demonstrated good intra-rater, inter-rater and test-retest reliability (ICC $=0.98$ for all three cases) and high internal consistency (Cronbach's alpha $=0.96)$ [43]. It has good convergent validity with the Chedoke-McMaster Stroke Assessment [47] for leg and foot $(r=0.61$ and 0.63, 
respectively) and for lower extremity strength $(\mathrm{r}=0.67)$ [44]. Furthermore, the CB\&M has been shown to be sensitive to change from baseline at follow-up in community-dwelling, ambulatory individuals post-stroke (SRM (standardized response mean $)=0.83$ ) [44]. In addition, the Berg Balance Scale $[42,48]$ will be used to evaluate balance in patients. The Four-Squares Test will also be used. This test consists of moving in different preset directions: forward, backward and to the sides. The time required to complete the sequence is recorded. An execution time greater than 15 seconds is predictive of falling. This test has high inter-rater $(\mathrm{ICC}=0.99)$, intrarater $(\mathrm{ICC}=0.98)$ and test-retest $(\mathrm{ICC}=0.98)$ reliability in community-dwelling older individuals aged 65 years and over [49]. Also, for predicting falls, this test has good specificity ranging from $88 \%$ to $100 \%$ and a positive predictive value of $86 \%$ [49].

The physical abilities capacities measured will be: 1) walking speed, 2) walking endurance, 3) lower extremity strength, and 6) lower extremity movement capacity. Each of these abilities plays an important role in achieving optimal functional mobility. Walking speed will be evaluated using the Timed Up and Go test (TUG) [50]. The test consists of standing up from a chair, walking a distance of three meters, turning around and returning to the chair to sit down again. The test is timed to measure walking speed in seconds over a distance of six meters. The TUG demonstrates good convergent construct validity with moderate to strong correlations with walking using the Tinetti test $(r=0.53)$ and walking speed $(r=0.66)$ in an elders population aged 65 years and over [51]. It has also been shown that walking speed is related to use of gait aids and fall frequency [52]. It is a measure sensitive to change [53]. Walking endurance will be estimated by the distance covered in meters during the Two-Minute Walk Test $[53,54]$. The inter-rater and intra-rater reliability of this test is high (ICC =0.99) [50]. General lower extremity strength will be measured with the Sit to Stand test (STS) [55]. The time required to complete five successive 'sit-tostand' repetitions will be recorded $[55,56]$. The test-retest reliability of the STS is high (ICC =0.89) [57]. There is also a strong correlation of the STS with walking speed over five meters $(\mathrm{r}=-0.66)$ and lower extremity strength $(r=0.47)$ [58]. Lower extremity movement capacity and postural control will be evaluated using the ChedokeMcMaster Stroke Assessment [59]. The impairment inventory determines the presence and severity of physical deficits, and allows patients to be classified according to Brunnstrom's seven stages of motor recovery. This tool has good intra- and inter-rater reliability (ICC $=0.98$ and 0.97 , respectively) and good construct validity $(r>0.60$ with different aspects of the Fugl Meyer test) [47].

Two main aspects of psychological capacities measured will be 1) fear of falling, and 2) self-efficacy. The simplified version of the Activities-specific Balance Confidence $(\mathrm{ABC})$ scale [60] questionnaire (ABC-S) will measure fear of falling. This questionnaire includes 15 questions rated on a four-point Likert scale and evaluates an individual's balance confidence during a series of daily activities [60,61]. The ABC-S has strong internal consistency (Cronbach's alpha $=0.86$ ) good convergent validity with significant associations with balance and occurrence of falls [60]. Self-efficacy when faced with difficult life situations will be evaluated using the Generalized Self-Efficacy Scale (GSES) [60]. This questionnaire is a ten-item scale that uses a four-point Likert scale (from $1=$ not true at all, to $4=$ completely true) to assess whether an individual believes that their actions are responsible for their successful outcomes. This scale has been shown to have excellent internal consistency (Cronbach's alpha $=0.86$ ) [62].

Quality of life will be measured using the Reintegration to Normal Living Index (RNLI) [63]. This tool consists of 11 items ranked on a three-point Likert scale. The total score ranges from 0 to 22 , with higher scores depicting lower quality of life. The psychometric properties range from very good to excellent with good internal consistency (Cronbach's alpha $=0.90$ ) and good testretest reliability $(r=0.83)$ [63]. The construct validity of this tool has been examined in a post-stroke population and shows excellent correlations with the Frenchay Activities Index $(r=0.69)$ and the Short Form 36 Health Survey $(r=0.74)[64]$.

Participant satisfaction with the intervention received will be evaluated using the Health Care Satisfaction Questionnaire, a questionnaire developed and validated in French [65]. The satisfaction construct is determined by three distinct factors which include satisfaction with: 1) the therapist relationship, 2) the services provided, and 3) the organization of services. This tool includes 26 questions, scored on a four-point Likert scale. The total score is calculated based on average satisfaction for the three factors, with higher scores indicating higher levels of satisfaction. Test-retest reliability is documented by an ICC of 0.72 and internal consistency by a Cronbach's alpha of 0.93 for the entire scale [65].

A modified version of the 'Cost analysis of telemedicine' table from the University of Minnesota [66] will help tabulate the costs associated with the teletreatments. These costs will be calculated to establish a cost differential (that is, cost-effectiveness) between the two different types of intervention. The method for collecting this data has already been tested in a previous study [67]. The variables related to the total cost include those associated with the actual intervention (for example, direct and indirect time for the intervention, professionals' travel time to the participants' homes, telerehabilitation equipment, and Internet service including installation and set-up). 
The typical sociodemographic (for example, age, sex, marital status, living environment, education, primary occupation) and clinical characteristics (for example, diagnosis, gait aid, medications, self-rated health, co-morbidities) will be collected using an in-house questionnaire, with the exception of comorbidities for which the Functional Comorbidity Index will be used [68].

The level of impairment post-stroke will be measured by the National Institute of Health Stroke Score (NIHSS) $[69,70]$. This questionnaire, administered by a healthcare professional, includes 15 items to evaluate patients in the acute post-stroke phase. It demonstrates good internal consistency (Cronbach's alpha $>0.5$ ) [71], good inter-rater $(\mathrm{ICC}=0.69)$ and test-retest (ICC $=0.66$ to 0.77$)$ reliability in a post-stroke population [69] and good convergent validity $(r=0.74$ with lesion volume seven days post-stroke) [70]. The level of cognitive impairment will be measured using the Montreal Cognitive Assessment (MoCA) [72]. This test evaluates attention, concentration, executive functions, memory, language, visioconstructive capacities, abstraction capacities, calculation and orientation. The maximum score of 30 corresponds to no cognitive problems. The internal consistency of this test is good (Cronbach's alpha $=0.83$ ) and test-retest reliability is excellent $(\mathrm{ICC}=0.92)$ [73]. The correlation between the MoCA and Mini-Mental State Examination scores has been shown to be excellent $(r=0.87)$ [73]. Noteworthy is the fact that this test will be completed during the participant recruitment phase.

\section{Statistical methods}

We expect to recruit 240 participants, that is, 120 per group. Allowing for a drop-out rate of $10 \%$, this sample size will provide a power of $80 \%$ to demonstrate the non-inferiority of Tai Chi provided by telerehabilitation compared to Tai Chi provided in person at home, with a two-group one-sided test at the 2.5\% level (nQuery Advisor 7.0; Statistical Solutions, Boston, MA). For this calculation, the non-inferiority limit was set at four points on the CB\&M scale and the standard deviation of the gain was estimated to be 10.4, based on findings from Knorr [44], since SRM $=$ Mean $_{\mathrm{GAIN}} / \mathrm{s}_{\mathrm{GAIN}}$ implies that:

$$
\mathrm{S}_{\mathrm{GAIN}}=\mathrm{Mean}_{\mathrm{GAIN}} / \mathrm{SRM}=(51.3-42.7) / 0.83
$$

First, we will describe the characteristics of each group pre-intervention using averages and standard deviations (continuous variables) or percentages (categorical variables). The groups will then be compared using a $t$-test or chi-squared test. If the groups differ on certain characteristics pre-intervention despite randomization, subsequent analyses will account for these differences.

Primary analysis will aim to test the non-inferiority of Tai Chi provided via telerehabilitation compared to Tai
Chi provided in person at home as evaluated by score gains on the CB\&M questionnaire from T1 to T2. Delivery by telerehabilitation will be regarded as non-inferior to in person home delivery if the upper limit of the unilateral confidence interval around the difference in gains between the two groups is less than 4 . This noninferiority limit was set below the CB\&M's minimal clinically significant difference of five points. It is recommended to choose a non-inferiority limit less than the difference judged to be clinically significant $[74,75]$.

The same analytical strategy will be used to evaluate and compare the effectiveness of the interventions on secondary variables and to compare maintenance over time (that is, the confidence interval around the difference between the two groups from T1 to T3) across all variables. A more conservative level of significance will be used to account for the numerous tests.

All analyses will first be performed according to the treatment received (per protocol $=\mathrm{PP}$ ) and according to the assigned group (intention to treat $=$ ITT), requiring that non-inferiority be shown in both cases since ITT analyses increase the chance of declaring non-inferiority if the two delivery modes produce a similar pattern of withdrawal, while PP analyses bias towards the null in presence of a different pattern of withdrawal [74]. For the ITT analysis, the effects of withdrawal or low levels of compliance will be explored with sensitivity analyses, where the missing data will be replaced with extreme values (that is, no change following treatment - the most favorable change noted in the study). Any non-robustness of results revealed by the comparison of strategies will be noted and the caveats will be mentioned in the discussion of results. All analyses will be conducted at the end of the study since the proposed treatments are of short duration and involve minimal risk to the participants.

The economic analysis will be a type of costminimization study [76]. Assuming that the effectiveness will be the same in the dependent variable (CB\&M), the cost will be determined for the two groups and the cost differential will be established.

\section{Discussion}

This trial is the first large-scale study to evaluate the noninferiority of telerehabilitation versus home visits in patients with mild to moderate balance impairment poststroke. Confirmation to recruit as many as 240 patients post-stroke with our inclusion/exclusion criteria is based on the 2010 to 2011 statistics for each recruitment site: 1) Centre Hospitalier Universitaire de Sherbrooke (269 participants admitted following a stroke, including 59 who returned home upon discharge); 2) Jewish Rehabilitation Hospital (277 referrals for patients post-stroke); 3) Centre de Santé et de Services Sociaux Champlain-Charles-Le Moyne (106 participants admitted following a stroke, 
including 60 who returned home upon discharge); 4) Toronto (189 participants admitted following a stroke, including 49 who returned home upon discharge). These well-documented statistics proved the realism of the scope of the study.

Telehealth, which includes telerehabilitation, is seen as a method to provide care to the population. Considering that the criteria for quality of care remain the same regardless of whether the care is provided by telehealth or other means, the evaluation framework of the proposed research is based on the theoretical construct of quality of care. Without formal definition [77], quality of care encompasses two components: 1) the viewpoint of the patient who considers the notions of accessibility and effectiveness as essential [78]; and 2) the viewpoint of the professional for whom the patient-doctor relationship [79], efficiency and reliability are of key importance. Several conceptual models for evaluating quality of care in the literature include the Donabedian [80], Total Quality Management [81], Quality-Caring [82], ORYX [80], HEDIS [83] and CONQUEST [80] models. In this research project, the conceptual evaluation model used will be the Donabedian model [84]. Given the objectives of this project, the study aims to answer specific questions related to the effectiveness of using telerehabilitation to improve quality of care for older individuals. This model defines quality of care as a combination of three elements: structure, process and outcome. The notions of 'quality' and 'performance' are directly related to the organizational structure of the healthcare system and its management processes. The term 'outcome' corresponds to the quality of care provided to patients, the performance of the healthcare system in offering care and the associated costs. Given the nature of this research, emphasis will be placed on the evaluation of telerehabilitation outcomes.

Concerning internal validity, we will control for potential selection bias by assigning participants to either the telerehabilitation or the control (home visits) group by randomization and by comparing participants' characteristics in each group before the intervention. If the groups have different characteristics pre-intervention despite randomization, subsequent analysis will account for these differences. Information bias will be controlled by using standardized measures and by calibrating all the assessors for each assessment.

This study will verify the non-inferiority of in-home telerehabilitation compared to home visits for patients with mild to moderate balance problems post-stroke. Our hypothesis is that in-home telerehabilitation will be shown to be a good alternative to ensure continuity of rehabilitation services and their accessibility in the community.

\section{Trial status}

Recruitment has just begun (September 2013).

\section{Abbreviations}

ABC-S: Activities-specific Balance Confidence scale (Simplified version), CB\&M: Community Balance and Mobility Scale; GSES: Generalized Self-Efficacy Scale; ICC: intra-class correlation; IFRU: Intensive Functional Rehabilitation Unit; ITT: intention to treat; MoCA: Montreal Cognitive Assessment; NIHSS: National Institute of Health Stroke Score; PP: per protocol; RCT: randomized controlled trial; RNLI: Reintegration to Normal Living Index; SRM: standardized response mean; STS: Sit to Stand test; TUG: Timed Up and Go test.

\section{Competing interests}

The authors declare that they have no competing interests.

\section{Authors' contributions}

All authors participated in the conception and design of the study. MT is responsible for telerehabilitation expertise. $\mathrm{HC}$ and $\mathrm{KB}$ are responsible for fall prevention, balance expertise and intervention program. SG and RS are the neurologists taking care of recruitment. DK carries out the cost evaluation MFD carries out the statistical analysis. JMB and CD supervised the team of research agents at their sites. All authors read and approved the final manuscript.

\section{Acknowledgements}

This research project is support by a grant received from the Canadian Institute of Health Research (CIHR), CIHR grant \#272977.

\section{Author details}

${ }^{1}$ Université de Sherbrooke, Sherbrooke, QC, Canada. ${ }^{2}$ Research Center on Aging, University Institute of Geriatrics of Sherbrooke, Sherbrooke, QC, Canada. ${ }^{3}$ Université de Montréal, Montreal, QC, Canada. ${ }^{4}$ University of Toronto, Toronto, ON, Canada. ${ }^{5}$ Sunnybrook Stroke Research Unit, Toronto, ON, Canada.

Received: 3 October 2013 Accepted: 22 January 2014

Published: 30 January 2014

\section{References}

1. Sacco RL, Benjamin EL, Broderick JP, Dyken M, Eston JD, Feinberg WM, Goldstein LB, Gorelick PB, Howard G, Kittner SJ, Manolio TA, Whisnant JP, Wolf PA: American Heart Association Prevention Conference. IV. Prevention and Rehabilitation of Stroke. Risk factors. Stroke 1997, 28(7):1507.

2. Dimyan MA, Cohen LG: Neuroplasticity in the context of motor rehabilitation after stroke. Nat Rev Neurol 2011, 7(2):76

3. Forster A, Young J: Stroke rehabilitation: can we do better? BMJ 1992, 305(6867):1446.

4. Wada N, Sohmiya M, Shimizu T, Okamoto K, Shirakura K: Clinical analysis of risk factors for falls in home-living stroke patients using functional evaluation tools. Arch Phys Med Rehabil 2007, 88(12):1601.

5. Stolze H, Klebe S, Zechlin C, Baecker C, Friege L, Deuschl G: Falls in frequent neurological diseases - prevalence, risk factors and etiology. J Neurol 2004, 251(1):79.

6. Lamb SE, Ferrucci L, Volapto S, Fried LP, Guralnik JM, Women's Health and Aging Study: Risk factors for falling in home-dwelling older women with stroke: the Women's Health and Aging Study. Stroke 2003, 34(2):494.

7. Simpson LA, Miller WC, Eng JJ: Effect of stroke on fall rate, location and predictors: a prospective comparison of older adults with and without stroke. PloS One 2011, 6(4):e19431.

8. Tinetti ME, Baker DI, Dutcher J, Vincent JE, Rozett RT: Reducing the risk of falls among older adults in the community. Berkeley, CA: Peaceable Kingdom Press; 1997.

9. Gillespie LD, Robertson MC, Gillespie WJ, Sherrington C, Gates S, Clemson $L M$, Lamb SE: Interventions for preventing falls in older people living in the community. Cochrane Database Syst Rev 2012, 9, CD007146.

10. Lincoln NB, Gladman JR, Berman P, Luther A, Challen K: Rehabilitation needs of community stroke patients. Disabil Rehabil 1998, 20(12):457-463.

11. Canadian Stroke Network: La qualité des soins de I'AVC au Canada. http:// www.canadianstrokenetwork.ca/wp-content/uploads/2011/06/OoSC-FR1.pdf.

12. Bates B, Choi JY, Duncan PW, Glasberg JJ, Graham GD, Katz RC, Lamberty K, Reker D, Zorowitz R, US Department of Defense; Department of Veterans Affairs: Veterans Affairs/Department of Defense Clinical Practice 
Guideline for the Management of Adult Stroke Rehabilitation Care: executive summary. Stroke 2005, 36(9):2049.

13. Edwards DF, Hahn MG, Baum CM, Perlmutter MS, Sheedy C, Dromerick AW: Screening patients with stroke for rehabilitation needs: validation of the post-stroke rehabilitation guidelines. Neurorehabil Neural Repair 2006, 20(1):42

14. Mayo NE, Wood-Dauphinee S, Côté R, Durcan L, Carlton J: Activity, participation, and quality of life six months poststroke. Arch Phys Med Rehabil 2002, 83(8):1035.

15. Chuang KY, Wu SC, Ma AH, Chen YH, Wu CL: Identifying factors associated with hospital readmissions among stroke patients in Taipei. J Nurs Res 2005, 13(2):117.

16. Thorsen AM, Holmqvist LW, de Pedro-Cuesta J, von Koch L: A randomized controlled trial of early supported discharge and continued rehabilitation at home after stroke: five-year follow-up of patient outcome. Stroke 2005, 36(2):297.

17. Lindsay P, Bayley M, Hellings C, Hill M, Woodbury E, Philips S: Recommandations canadiennes pour les pratiques optimales de soins de I'AVC (mise à jour de 2008) - Sommaire. CMAJ 2008, 179(12):SF1.

18. Ministère de la santé et des services sociaux du Québec: Chez soi: le premier choix. La politique de soutien à domicile. http://publications. msss.gouv.qc.ca/acrobat/f/documentation/2002/02-704-01.pdf.

19. Ministère de la santé et des services sociaux du Québec: Chez soi: le premier choix. Précisions pour favoriser l'implantation de la politique de soutien à domicile. http://publications.msss.gouv.qc.ca/acrobat/f/ documentation/2004/04-704-01.pdf

20. Hogenbirk JC, Brockway PD, Finley J, Jennett P, Yeo M, Parker-Taillon D, Pong RW, Szpilfogel CC, Reid D, MacDonald-Rencz S, Cradduck T: Framework for Canadian telehealth guidelines: summary of the environmental scan J Telemed Telecare 2006, 12(2):64.

21. Pineau G, Moqadem K, St-Hilaire C, Levac E, Hamel BT: Lignes directrices cliniques et normes technologiques en téléréadpatation, in Agences des technologies et des modes d'intervention en santé. http://www.inesss.qc. ca/fileadmin/doc/AETMIS/Rapports/Telesante/2006_03_res_fr.pdf.

22. Brennan D, Mawson S, Brownsell S: Telerehabilitation: enabling the remote delivery of healthcare, rehabilitation, and self management Stud Health Technol Inform 2009, 145:231.

23. McCue M, Fairman A, Pramuka M: Enhancing quality of life through telerehabilitation. Phys Med Rehabil Clin N Am 2010, 21(1):195.

24. Theodoros D, Russell T: Telerehabilitation: current perspectives. Stud Health Technol Inform 2008, 131:191.

25. Romanow RJ: L'Avenir des soins de santé au Canada. http://publications. gc.ca/collections/Collection/CP32-85-2002F.pdf

26. Wong AM, Yu-Cheng P, Ching L, Shu-Chun H, Yin-Chou L, Shih-Wei C: Is Tai Chi Chuan effective in improving lower limb response time to prevent backward falls in the elderly? Age (Dordr) 2009, 31(2):163.

27. Sattin RW, Sley KA, Wolf SL, Chen Y, Kutner MH: Reduction in fear of falling through intense Tai Chi exercise training in older, transitionally frail adults. J Am Geriatr Soc 2005, 53:1168.

28. Corriveau H, Sveistrup H, Tousignant M: Effects of Tai Chi Exercise on Clinical Measures of Balance and Attention Demand in Older Individuals with Moderate Diabetic Peripheral Neuropathy. Burlingon (USA): Proceedings of Symposium International of gait and posture: 3 to 5 July 2007; 2007.

29. Tousignant M, Corriveau H, Roy PM, Desrosiers J, Dubuc N, Hébert R: Efficacy of supervised Tai Chi exercises versus conventional physical therapy exercises in fall prevention for frail older adults: a randomized controlled trial. Disabil Rehabil 2012, 35(17):1429.

30. Tousignant M, Corriveau H, Roy PM, Desrosiers J, Dubuc N, Hébert R, Tremblay-Boudreault V, Beaudoin AJ: The effect of supervised Tai Chi intervention compared to a physiotherapy program on fall-related clinical outcomes: a randomized clinical trial. Disabil Rehabil 2012, 34(3):196.

31. Au-Yeung S, Hui-Chan CW, Tang JC: Short-form Tai Chi improves standing balance of people with chronic stroke. Neurorehabil Neural Repair 2009, 23(5):515-522

32. Har J, Kanner H, Gilboa-Mayo R, Haroeh-Peer O, Rozenthul-Sorokin N, Eldar R: Tai Chi Chuan practice in community-dwelling persons after stroke. Int J Rehabil Res 2004, 27(4):303.

33. $\mathrm{Wu} \mathrm{G}$, Keyes LM: Group tele-exercise for improving balance in elders. Telemed J E Health 2006, 12:561-570.

34. Wooton A: An integrative review of Tai Chi research: an alternative form of physical activity to improve balance and prevent falls in older adults. Orthop Nurs 2010, 29(2):108.
35. Bashshur R, Shannon G, Krupinski E, Grigsby J: The taxonomy of telemedicine. Telemed J E Health 2011, 17(6):484.

36. Tousignant M, Boissy P, Moffet $H$, Corriveau H, Cabana F, Marquis F, Simard $\mathrm{J}$ : Patients' satisfaction of healthcare services and perception with inhome telerehabilitation and physiotherapists' satisfaction toward technology for post-knee arthroplasty: an embedded study in a randomized trial. Telemed J E Health 2011, 17(5):376.

37. Dechêne L, Tousignant M, Boissy P, Macoir J, Héroux S, Hamel M, Brière $S$, Pagé C: Simulated in-home teletreatment for anomia. Int J Telerehabil 2011, 3(2):3

38. Tousignant M, Marquis N, Pagé C, Imukuze N, Métivier A, St-Onge V, Tremblay A: In-home telerehabilitation for older persons with chronic obstructive pulmonary disease: a pilot Study. Int J Telerehabil 2012, 4(1):7

39. Lai SM, Duncan PW: Stroke recovery profile and the Modified Rankin assessment. Neuroepidemiology 2001, 20(1):26.

40. Berg K, Wood-Dauphinee S, Williams J: The Balance Scale: reliability assessment with elderly residents and patients with an acute stroke. Scand J Rehabil Med 1995, 27(1):27.

41. Wolf SL, Coogler C, Xu T: Exploring the basis for Tai Chi Chuan as a therapeutic exercise approach. Arch Phys Med Rehabil 1997, 78(8):886.

42. Lubetzky-Vilnai A, Kartin D: The effect of balance training on balance performance in individuals poststroke: a systematic review. J Neurol Phys Ther 2010, 34(3):127.

43. Howe JA, Inness EL, Venturini A, Williams JI, Verrier MC: The Community Balance and Mobility Scale - a balance measure for individuals with traumatic brain injury. Clin Rehabil 2006, 20(10):885.

44. Knorr S, Brouwer B, Garland SJ: Validity of the Community Balance and Mobility Scale in community-dwelling persons after stroke. Arch Phys Med Rehabil 2010, 91(6):890.

45. Salbach NM, Mayo NE, Higgins J, Ahmed S, Finch LE, Richards CL: Responsiveness and predictability of gait speed and other disability measures in acute stroke. Arch Phys Med Rehabil 2001, 82(9):1204.

46. Rocque R, Bartlett D, Brown J, Garland SJ: Influence of age and gender of healthy adults on scoring patterns on the Community Balance and Mobility Scale. Physiother Can 2005, 57:285.

47. Gowland C, Stratford P, Ward M, Moreland J, Torresin W, Van Hullenaar S, Sanford J, Barreca S, Vanspall B, Plews N: Measuring physical impairment and disability with the Chedoke-McMaster Stroke Assessment. Stroke 1993, 24(1):58

48. Blum L, Korner-Bitensky N: Usefulness of the Berg Balance Scale in stroke rehabilitation: a systematic review. Physical therapy 2008, 88(5):559.

49. Dite $W$, Temple VA: A clinical test of stepping and change of direction to identify multiple falling older adults. Arch Phys Med Rehabil 2002, 83(11):1566

50. Podsiadlo D, Richardson S: The timed 'Up \& Go': a test of basic functional mobility for frail elderly persons. J Am Geriatr Soc 1991, 39(2):142.

51. Lin MR, Hwang HF, Hu MH, Wu HD, Wang YW, Huang FC: Psychometric comparisons of the timed up and go, one-leg stand, functional reach, and Tinetti balance measures in community-dwelling older people. J Am Geriatr Soc 2004, 52(8):1343.

52. Wade DT, Wood VA, Heller A, Maggs J, Langton Hewer R: Walking after stroke. Measurement and recovery over the first three months. Scand J Rehabil Med 1987, 19(1):25.

53. Dean CM, Richards CL, Malouin F: Walking speed over 10 meters overestimates locomotor capacity after stroke. Clin Rehabil 2001, 15(4):415.

54. Wade DT: Measurement in neurological rehabilitation. Curr Opin Neurol Neurosurg 1992, 5(5):682.

55. Bohannon RW: Sit-to-stand test for measuring performance of lower extremity muscles. Percept Mot Skills 1995, 80(1):163.

56. Csuka M, McCarty DJ: Simple method for measurement of lower extremity muscle strength. Am J Med 1985, 78(1):77

57. Lord SR, Murray SM, Chapman K, Munro B, Tiedemann A: Sit-to-stand performance depends on sensation, speed, balance, and psychological status in addition to strength in older people. J Gerontol A Biol Sci Med Sci 2002, 57(8):M539.

58. Newcomer KL, Krug HE, Mahowald ML: Validity and reliability of the timed-stands test for patients with rheumatoid arthritis and other chronic diseases. J Rheumatol 1993, 20(1):21.

59. Valach L, Signer S, Hartmeier A, Hofer K, Steck GC: Chedoke-McMaster stroke assessment and modified Barthel Index self-assessment in patients with vascular brain damage. Int J Rehabil Res 2003, 26(2):93. 
60. Filiatrault J, Gauvin L, Fournier M, Parisien M, Robitaille Y, Laforest S, Corriveau $\mathrm{H}$, Richard L: Evidence of the psychometric qualities of a simplified version of the Activities-specific Balance Confidence scale for community-dwelling seniors. Arch Phys Med Rehabil 2007, 88(5):664.

61. Jorstad EC, Hauer K, Becker C, Lamb SE, ProFaNE Group: Measuring the psychological outcomes of falling: a systematic review. J Am Geriatr Soc 2005, 53(3):501.

62. Scholz U, Gutiérrez-Doña B, Sud S, Schwarzer R: Is general self-efficacy a universal construct? Psychometric findings from 25 countries. Eur $J$ Psychol Ass 2002, 18(3):242.

63. Wood-Dauphinee SL, Opzoomer MA, Williams Jl, Marchand B, Spitzer WO: Assessment of global function: the Reintegration to Normal Living Index. Arch Phys Med Rehabil 1988, 69(8):583.

64. Daneski K, Coshall C, Tilling K, Wolfe CD: Reliability and validity of a postal version of the Reintegration to Normal Living Index, modified for use with stroke patients. Clin Rehabil 2003, 17(8):835.

65. Gagnon M, Hebert R, Dubé M, Dubois MF: Development and validation of an instrument measuring individual empowerment in relation to personal health care: the Health Care Empowerment Questionnaire (HCEQ). Am J Health Promot 2006, 20(6):429.

66. Chapko MK, Hedrick S: Cost as a study outcome: sensitivity of study conclusions to the method of estimating cost. Med Care 1999, 37(4 Suppl Va):AS37.

67. Tousignant M, Moffet $H$, Boissy B, Cooriveau H, Cabana F, Marquis F: A randomized controlled trial of home telerehabilitation for post-knee arthroplasty. J Telemed Telecare 2011, 17(4):195.

68. Groll DL, To T, Bombardier C, Wright JG: The development of a comorbidity index with physical function as the outcome. $J$ Clin Epidemiol 2005, 58(6):595.

69. Brott T, Adams JR, Olinger CP, Marler JR, Barsan WG, Biller J, Spilker J, Holleran R, Eberle R, Hertzberg V: Measurements of acute cerebral infarction: a clinical examination scale. Stroke 1989, 20:864-870.

70. Lyden P, Brott T, Tilley B, Welch KM, Mascha EJ, Levine S, Haley EC, Grotta J, Marler J: Improved reliability of the NIH Stroke Scale using video training. NINDS TPA Stroke Study Group. Stroke 1994, 25(11):2220.

71. Goldstein LB, Bertels C, Davis JN: Interrater reliability of the NIH stroke scale. Arch Neurol 1989, 46(6):660.

72. Pendlebury ST, Cuthbertson FC, Welch SJ, Mehta Z, Rothwell PM: Underestimation of cognitive impairment by Mini-Mental State Examination versus the Montreal Cognitive Assessment in patients with transient ischemic attack and stroke: a population-based study. Stroke 2010, 41(6):1290.

73. Nasreddine ZS, Phillips NA, Bédirian V, Charbonneau S, Whitehead V, Collin I, Cummings $\lrcorner$, Chertkow H: The Montreal Cognitive Assessment, MoCA: a brief screening tool for mild cognitive impairment. J Am Geriatr Soc 2005, 53(4):695.

74. Piaggio G, Elbourne DR, Pocock SJ, Evans SJ, Altman DG, CONSORT Group: Reporting of noninferiority and equivalence randomized trials: extension of the CONSORT 2010 statement. JAMA 2012, 308:2594.

75. Jones $B$, Jarvis $P$, Lewis JA, Ebbutt AF: Trials to assess equivalence: the importance of rigorous methods. BMJ 1996, 313(7048):36.

76. Drummond MF, O'Brien B, Stoddart GL, Torrance GW: Methods for the Economic Evaluation of Health Care Programmes. 2nd edition. Oxford: Oxford University Press; 1997.

77. Harteloh PP: The meaning of quality in health care: a conceptual analysis. Health Care Anal 2003, 11(3):259.

78. Campbell SM, Roland MO, Buetow SA: Defining quality of care. Soc Sci Med 2000, 51(11):1611.

79. Fleishman R: Non-medical predictors of quality of care of hypertension in elderly patients. Int J Health Care Qual Assur Inc Leadersh Health Serv 1997 10(2-3):107.

80. Larson JS, Muller A: Managing the quality of health care. $J$ Health Hum Serv Adm 2002, 25(3):261.

81. Zonsius MK, Murphy M: Use of total quality management sparks staff nurse participation in continuous quality improvement. Nurs Clin North Am 1995, 30(1):1.
82. Duffy JR, Hoskins LM: The quality-caring model: blending dual paradigms. ANS Adv Nurs Sci 2003, 26(1):77

83. Kennedy K, Mirmirani S, Spivack R: Continuous quality improvement in health maintenance organizations: an application of the HEDIS model. Int J Health Care Qual Assur 1996, 9(4):4.

84. Tasso K, Behar-Horenstein LS, Aumiller A, Gamble K, Grimaudo N, Guin P, Mandell T, Ramey B: Assessing patient satisfaction and quality of care through observation and interview. Hospital Topic 2002, 80(3):4.

doi:10.1186/1745-6215-15-42

Cite this article as: Tousignant et al:: Tai Chi-based exercise program provided via telerehabilitation compared to home visits in a post-stroke population who have returned home without intensive rehabilitation: study protocol for a randomized, non-inferiority clinical trial. Trials 2014 15:42

\section{Submit your next manuscript to BioMed Central and take full advantage of:}

- Convenient online submission

- Thorough peer review

- No space constraints or color figure charges

- Immediate publication on acceptance

- Inclusion in PubMed, CAS, Scopus and Google Scholar

- Research which is freely available for redistribution 